\title{
The Wise King.
}

\section{A Christian Prince, Muslim Spain, and the Birth of the Renaissance}

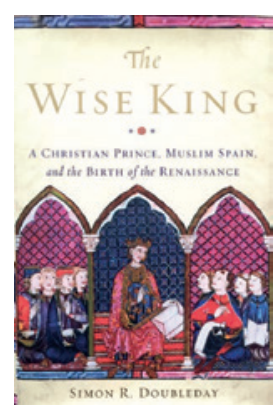

Simon R. Doubleday, The Wise King. A Christian Prince, Muslim Spain, and the Birth of the Renaissance, New York, Basic Books, 2015, 304 páginas.

Simon R. Doubleday, profesor de la Universidad de Hofstra (Nueva York) y editor de Journal of Medieval Iberian Studies, publicó hace unos meses The Wise King, una preciosa aportación sobre el Rey Sabio y su tiempo. No se trata de una biografia al estilo de la publicada por el profesor Manuel González Jiménez en $2004^{1}$, excelente culminación de una vida de trabajo dedicada al monarca, pero aborda con rigor su figura, su entorno familiar y palaciego, el gobierno del reino

1 Manuel GonzÁlez Jiménez, Alfonso X el Sabio, Barcelona, Ariel, 2004. 
castellano, su ambición imperial, sus logros intelectuales y culturales, etc.Y, sobre todo, en el conjunto de su obra, resulta admirable cómo el autor es capaz de trasladarnos a lo más íntimo de su personalidad, al mundo de las emociones que rodean su vida personal y familiar, sus decisiones políticas o su trabajo intelectual.

La contribución de Simon R. Doubleday toma como referencia, por supuesto, la abundante bibliografia sobre Alfonso X: las biografias, la documentación publicada, el itinerario real, la crónica, los análisis sobre su intereses en el Imperio o sobre el gobierno del reino y, cómo no, los estudios en torno a su actividad como impulsor de la ciencia, de la cultura, de la literatura, de la historia o de la música. Pero también maneja directamente la "General Estoria», las «Cantigas», el «Libro de los juegos», el «Lapidario» o el largo etcétera de textos producidos en el taller alfonsí. Si los primeros le permiten trasladar los datos y las interpretaciones fundamentales sobre Alfonso X, su relato alcanza mayor altura cuando toma como referencia las fuentes primarias. Abre con ellas las puertas de la cámara real y penetra en su intimidad: en los momentos felices junto a Violante, en la educación de sus hijos, en las tareas de gobierno o en el trabajo intelectual. Pero también en el dolor de su enfermedad, con motivo de la muerte repentina de su primogénito Fernando, en la violencia desplegada frente a quienes le habían traicionado al final de su reinado o en la amarga etapa final durante la rebelión de su hijo Sancho.

El subtítulo del libro recoge los grandes argumentos en torno a los que el autor lo ha organizado. En primer lugar, el retrato de Alfonso como príncipe cristiano que aspira tanto a situarse al frente del Sacro Imperio como a jugar su rol de gobernante al frente de una parte sustancial del territorio peninsular gracias a las conquistas militares en el sur -recibidas en herencia de su padre-, a cuya integración en el reino dedicará buena parte de su tarea como gobernante y hábil negociador, ya fuera frente al reducto islámico granadino como al resto de los reinos peninsulares. En segundo lugar, su fascinación por la cultura andalusí. Doubleday mantiene que fue un catalizador vital que nutrió su pasión por la astronomía, por la ciencia médica, por el ajedrez, por la filosofía aristotélica traducida en su tiempo del árabe al latín, por la música o la poesía, pues las Cantigas de Santa María también registran la influencia de formas líricas andalusíes. Finalmente, el autor mantiene la tesis que esa admiración por lo andalusí pavimentó el camino que condujo al Renacimiento europeo.

A partir de estos argumentos cardinales, el autor divide su trabajo en nueve capítulos dedicados a asuntos centrales en la vida o en los intereses políticos, intelectuales o culturales del Rey Sabio -Players, Lovers, Stargazers, Hunters, Laughter, Friends, Father, Healers, Anger- en los que va entretejiendo -como ha señalado Jesús Rodríguez Velasco- los acontecimientos que jalonan la vida de su protagonista. El resultado es, a mi juicio, brillante y, pese a la pasión que el 
autor transmite por el personaje, en absoluto es un libro condescendiente con el Rey Sabio. Basta leer el último de sus capítulos para darse cuenta de ello cuando el autor narra el terrible final de Alfonso X: en el plano político -la rebelión de su hijo Sancho-y en el personal -su enfermedad, el abandono deViolante-

El libro no está dedicado exclusivamente a los especialistas, sino también al gran público que, particularmente en el caso del de habla inglesa, mantiene la idea de una cultura española fanáticamente religiosa e intolerante que ha oscurecido la figura de Alfonso X y sus contribuciones a la cultura global. Está muy bien escrito y el autor sabe captar de inmediato, ya desde el Prólogo, la atención de sus lectores, que quedan atrapados al descubrir cómo las «Siete Partidas» conforman un código comparable en su ambición a los de Justiniano o Napoleón o cómo sus trabajos de astronomía influyeron en Copérnico durante su etapa de estudiante en Cracovia. Una tarea que continúa en el Epílogo del libro, que puede leerse a continuación.

En definitiva, nos encontramos ante un original dedicado a un personaje y un tiempo que fueron cruciales en la historia peninsular y europea. Una lectura recomendable e imprescindible.

José Ramón Díaz de Durana

Universidad del País Vasco 